Article

\title{
Social Sustainability and Its Indicators through a Disability Studies and an Ability Studies Lens
}

\section{Gregor Wolbring ${ }^{1, *}$ and Theresa Rybchinski ${ }^{2}$}

1 Faculty of Medicine, Department of Community Health Sciences, Stream of Community Rehabilitation and Disability Studies, University of Calgary, 3330 Hospital Drive NW, Calgary, Alberta T2N4N1, Canada

2 Faculty of Medicine, University of Calgary, Calgary, Alberta T2N4N1, Canada; E-Mail: tkrybchi@ucalgary.ca

* Author to whom correspondence should be addressed; E-Mail: gwolbrin@ucalgary.ca; Tel.: +1-403-210-7083.

Received: 1 September 2013; in revised form: 29 October 2013 / Accepted: 11 November 2013 / Published: 14 November 2013

\begin{abstract}
The present journal recently stated in the call for a special issue on social sustainability, "[t]hough sustainable development is said to rest on 'three pillars', one of these - social sustainability — has received significantly less attention than its bio-physical environmental and economic counterparts". The current issue promises to engage the concepts of "development sustainability", "bridge sustainability" and "maintenance sustainability" and the tensions between these different aspects of social sustainability. The aim of the present study is to identify the visibility of disabled people in the academic social sustainability literature, to ascertain the impact and promises of social sustainability indicators put forward in the same literature and to engage especially with the concepts of "development sustainability", "bridge sustainability" and "maintenance sustainability" through disability studies and ability studies lenses. We report that disabled people are barely covered in the academic social sustainability literature; of the 5165 academic articles investigated only 26 had content related to disabled people and social sustainability. We also conclude that social sustainability indicators evident in the 1909 academic articles with the phrase "social sustainability" in the abstract mostly focused on products and did not reflect yet the goals outlined in the "development sustainability" aspect of social sustainability proposed by Vallance such as basic needs, building social capital, justice and so on. We posit that if the focus within the social sustainability discourse shifts more toward the social that an active presence of disabled people in this
\end{abstract}


discourse is essential to disabled people. We showcase the utility of an ability studies lens to further the development and application of the "development sustainability", "bridge sustainability" and "maintenance sustainability" concepts. We outline how different ability expectations intrinsic to certain schools of thought of how to deal with human-nature relationships (for example anthropocentric versus bio/ecocentric) impact this relationship and "bridge sustainability". As to "maintenance development", we posit that no engagement has happened yet with the ability expectation conflicts between able-bodied and disabled people, or for that matter with the ability expectation differences between different able-bodied groups within social sustainability discourses; an analysis essential for the maintenance of development. In general, we argue that there is a need to generate ability expectation conflict maps and ability expectations conflict resolution mechanisms for all sustainable development discourses individually and for ability conflicts between sustainable development discourses.

Keywords: social sustainability; disabled people; people with disabilities; disability studies; indicators; social determinants of health; ability studies

\section{Introduction}

Ever since the appearance of the Brundlandt report, which highlighted the importance of sustainable development (SD) [1], various endeavors have developed around SD [2]. Sustainable development is conceptualized to encompass three dimensions: environmental, economic and social [3]; however, it is acknowledged that social dimension has received less recognition in comparison to the economic and environmental aspects [3].

At the same time that a rigorous debate developed around the concept of environmental sustainability, its definition, indicators and measurements and its application and realization [4], it has been proposed that the situation is much less clear concerning social sustainability [4]. Numerous understandings exist as to what comprises social sustainability. McKenzie highlighted various definitions in his working paper Social Sustainability: Towards Some Definition [4] using the following working definition: "Social sustainability is: a life-enhancing condition within communities, and a process within communities that can achieve that condition."[4]. He furthermore identified the following indicators:

- equity of access to key services (including health, education, transport, housing and recreation);

- equity between generations, meaning that future generations will not be disadvantaged by the activities of the current generation;

- a system of cultural relations in which the positive aspects of disparate cultures are valued and protected, and in which cultural integration is supported and promoted when it is desired by individuals and groups;

- the widespread political participation of citizens not only in electoral procedures but also in other areas of political activity, particularly at a local level; 
- a system for transmitting awareness of social sustainability from one generation to the next;

- a sense of community responsibility for maintaining that system of transmission;

- mechanisms for a community to collectively identify its strengths and needs;

- mechanisms for a community to fulfill its own needs where possible through community action;

- mechanisms for political advocacy to meet needs that cannot be met by community action.

McKenzie's list of indicators is however only one of several lists of social sustainability indicators [5,6]. We discuss in this paper the potential usefulness of adding indicators used in two other discourses (social determinants of health [7]; social indicator of compliance with the United Nations Convention on the Rights of Persons with Disabilities [8]) to the list of social sustainability indicators.

According to Vallance, Perkins, and Dixon social sustainability is a concept to describe a collective understanding of the need to build a community in order for individuals to thrive with equal access to opportunities for individual development [3]. This includes the notion that it is a human right for all individuals to have access to basic needs and to promote the idea of "thriving" within a community instead "surviving" [3]. Vallance, Perkins, and Dixon have set forth the idea of three aspects of social sustainability: "development", "bridge" and "maintenance" [3]. According to Vallance, Perkins, and Dixon "development sustainability" addresses basic needs, the creation of social capital, justice and so on; "bridge sustainability" concerns itself with changes in behavior so as to achieve bio-physical environmental goals; and "maintenance sustainability" refers to the preservation — or what can be sustained - of sociocultural characteristics in the face of change, and the ways in which people actively embrace or resist those changes [3].

Article 32 of the United Nations Convention on the Rights of Persons with Disabilities covers the demand that international co-operation, including international development programs, must be inclusive of and accessible to persons with disabilities [9]. The United Nations General Assembly had numerous resolutions on the topic of the Millennium Development Goals (MDG's) and disabled people) [10] and the latest Secretary General report: Keeping the Promise: Realizing MDGs for Persons with Disabilities Towards 2015 and Beyond: Report of the Secretary-General (A/65/173) [11] had many recommendations . Furthermore, the recent High-Level Panel of Eminent Persons on the Post-2015 Development Agenda released the report A New Global Partnership: Eradicate Poverty and Transform Economics through Sustainable Development [12], which made clear that inclusion of all populations, including disabled people, is essential in addressing the overwhelming numbers of individuals impoverished in the world today [12]. This paper proposes to engage with the "development", "bridge", and "maintenance", aspects of social sustainability through a disability studies and an ability studies lens. We introduce the cultural dynamics of ability expectations (want stage) and ableism (need stage_-perceiving certain abilities as essential) [13], concepts originating from the disability rights movement and the disability studies field [14], but as a cultural phenomenon evident beyond the ability expectations covered within disability studies to "development", "bridge", and "maintenance", sustainability in particular and social sustainability in general. 


\section{Experimental Section}

\subsection{Analytical Framework}

\subsubsection{Analytical Framework of Disability Studies}

Disability Studies is an interdisciplinary/multidisciplinary academic discipline that investigates the situation disabled people face $[14,15]$. Disability studies is based on the premise that the problems disabled people face do not originate within their body but are a reflection of the societal reaction of so-called non-disabled people towards the ability differences disabled people exhibit.

\subsubsection{Analytical Framework of Ability Studies}

The disability community developed the cultural construct of ableism which highlights that people and groups have certain ability expectations [14]. Ability Studies originated from this root and is an inter/multidisciplinary field investigating how ability expectation and ableism hierarchies and preferences come to pass and the impact of such hierarchies and preferences [14,16,17]. "Ability studies investigates (a) which abilities are seen as essential in a given context, (b) the dynamic of how an ability expectation consensus is reached if it is reached and (c) the impact of ability expectations" [14,16-18]. Ability studies goes beyond body-related ability expectations which are the focus within the disability arena [14]. Social entities from individuals to societies as a whole [14] cherish numerous abilities (e.g., competitiveness, ability to consume, being productive, being able to live in harmony with nature), not just body-related abilities. Related to the topic of this call for papers, ability expectations have been described for education for sustainable development [17], waste and footprint [19], energy [20], Rio+20 discourse [21], ecohealth [22], ability privilege [18] and why disabled people are invisible as stakeholders in water discourses [23]. Indicators and other performance measures all exhibit ability expectations [17].

\subsection{Data Source}

\subsubsection{Social Sustainability}

We searched the following academic databases: Scopus, EBSCO (All), Web of Science, and JSTOR for the keyword "social sustainability". We searched the two databases Scopus and EBSCO (All) for the keyword in the abstract or in full text. The database Web of Science was searched for the keyword as topic (which included the full text) due to the lack of an option for searching abstracts. The database JSTOR was searched for the keyword also in the full text because according to JSTOR, abstracts were only provided for $10 \%$ of the articles in the database. Research Information Systems (RIS) files (including the abstracts) of identified articles were imported into the software Knowledge Share (KSv2) version 2.1.3 [24]. This software eliminated duplications as RIS files from the different databases were imported leading to 1909 abstracts of articles covering social sustainability. The 1909 abstracts were used for further data analysis, especially for identifying goals and indicators mentioned, using ATLAS.ti ${ }^{\odot}$ a qualitative analysis software. 


\subsubsection{Social Sustainability and Disabled People}

We searched the following academic databases: Scopus, EBSCO (All), Web of Science and JSTOR. We used the keyword combination "social sustainability" and various words related to disability. We used the root disab* to catch different disability terms. If a certain database could not deal with wildcards, we used individual terms such as disability, disabilities and disabled. As for Scopus, Web of Science and JSTOR we used the articles identified from the full text search with the keyword combination of social sustainability and various words related to disability. In the case of EBSCO (All) we used articles identified from the abstract search for the keyword social sustainability and full text search of various terms related to disability. The articles that were accessible through the University e-library were downloaded as PDF and imported into ATLAS.tiC for content analysis.

The number of full articles obtained from full text/full text searches of Scopus, Web of Science and JSTOR was small enough to download all of the articles and check the articles for relevance using ATLAS.tiC. We found that many of the articles had no relevance as they did not really focus on social sustainability and disabled people. When we used the same fulltext/full text combination search with EBSCO(All) it led to over 2000 hits which potentially could exhibit the same relevance problem as described for Scopus, Web of Science and JSTOR. We downloaded a few hits of the fulltext/full text combination search with EBSCO(All) and found that all articles were of no relevance as they were not about social sustainability and disabled people. Therefore we decided for EBSCO(All) to use articles that had "social sustainability" in the abstract and disability related terms in the full text to ensure greater relevance of the articles toward the topic of "social sustainability" and for a smaller pool of articles to download that could be checked for relevance as we did for Scopus, Web of Science and JSTOR full text articles.

\subsubsection{Social Sustainability and "Social Determinants of Health"}

Our search strategy was similar to the one described under Section 2.2.1 with the difference that the phrase "social determinants of health" was searched in combination with "social sustainability".

\subsection{Coding}

We used ATLAS.ti ${ }^{\odot}$, a qualitative data analysis software (CAQDAS) [25,26], for generating qualitative and quantitative data. After we imported all sources into ATLAS.ti ${ }^{\odot}$ we performed various coding strategies; one being a deductive strategy where we used a set of predetermined terms fitting the coding analytical framework of disability studies [14,15] and the research questions. This list allowed us through the auto-code function of ATLAS.ti ${ }^{\odot}$ to search all of our documents for a given word in one pass; for example all of our sources were searched for the terms impairment, disab* (catching disabled, disability, disabilities) and the term indicator. We also employed an inductive and iterative coding strategy, in which articles/abstracts were read and when a theme fitting the study was identified we used the free coding option to generate a phrase that represented the theme and added this phrase to the coding list.

At least two authors performed the coding to increase reliability, and differences were resolved during our discussions. 
Once coding was finished we used ATLAS.ti ${ }^{\odot}$ to generate the frequency of certain themes (quantitative data) and to generate a list of quotations of all sentences exhibiting certain words (qualitative data).

\subsection{Limitations}

Our limitation is that we only covered articles from certain academic databases.

\section{Results and Discussion}

\subsection{Visibility of Disabled People in the Academic Social Sustainability Discourse}

Visibility of disabled people in discourses is a key area of disability studies analysis. Table 1 highlights that disabled people were quite invisible to the social sustainability academic literature investigated.

Table 1. Frequency analysis of four databases and various terms relating to "disability" combined with the term "social sustainability".

\begin{tabular}{ccccc}
\hline Search Terms & $\begin{array}{c}\text { EBSCO All } \\
\text { all text/abstract }\end{array}$ & $\begin{array}{c}\text { Scopus abstract/ } \\
\text { all fields }\end{array}$ & $\begin{array}{c}\text { Web of Science } \\
\text { Whole topic }\end{array}$ & $\begin{array}{c}\text { JSTOR } \\
\text { full text }\end{array}$ \\
\hline $\begin{array}{c}\text { "Social sustainability" } \\
\text { "Social sustainability" +disab* }\end{array}$ & $8804 / 1920$ & $748 / 2307$ & 424 & 514 \\
(full text search) & $763 / 24$ & $10 / 58$ & 1 & 12 \\
$\begin{array}{c}\text { Disability and social sustainability } \\
\text { Disabled and social sustainability }\end{array}$ & $535 / 15$ & $7 / 47$ & 1 & 17 \\
$\begin{array}{c}\text { Disabilities and social sustainability } \\
\text { "Social Sustainability" and }\end{array}$ & $534 / 15$ & $4 / 21$ & 0 & 19 \\
"Social determinants of health" & $11 / 0$ & $7 / 47$ & 1 & 12 \\
\hline
\end{tabular}

Of the possible 5165 articles, after elimination of duplicates, 55 articles had disability related terms in the full text. Four articles were not accessible to us so 51 were used for content analysis.

Table 2 highlights that quite a few articles did not really cover disabled people or social sustainability and have to be seen as false positives. Of the 5165 articles, only 55 mentioned disabled people. Of the 55 articles, not every article covered the theme of social sustainability. Some articles that were identified by the searches to cover social sustainability were tallied as false positives as the term "social sustainability" showed up only in the reference section (Table 2). Various articles did not cover disabled people within the social sustainability theme (Table 2) although initial hits were obtained. In some cases this was due to the false positive of "disability". In some cases, the term disabled was not about disabled people but rather about entities such as a "disabled regulatory apparatus" [27]. In some cases, disability was not about disabled people as such but focused on disability adjusted life years (DALY) [28], disability insurance [29] or disability benefits [30]. The phrase "disabling globalization" showed up as a reference in [31].

As for the $n=26$ articles that cover both areas to a reasonable degree, the following content was covered. One article looked at disability policy in Afghanistan through the capability approach. The article argued that the transition from theory to action in human development has been low despite the 
evolution of the concept of human development. They used a recently performed National Disability Survey in Afghanistan to conclude that one reason for this shortcoming was lack and poor quality of existing data and lack of political and societal will "on enhancing the agency of vulnerable groups" [32]. One article highlighted the "[a]ccessible Helsinki Programme" and its focus on universal design which is about accessibility for everyone [33]. Another paper looked at criteria disabled people perceived as important for accommodations and how information should be presented [34]. One article thematized that evidence is missing that clearly shows that accessibility (for disabled people) as a goal is useful and they presented evidence that it is useful [35]. The lack of evidence as evident in many discourses [36] is broad and is a long-held concern by disabled people [37]. Darcy et al. wrote about "accessible tourism and its links with triple-bottom line (TBL) sustainability", that there is a need "to better understand the financial, environmental and social considerations that arise from accessible tourism" and that "a more sophisticated understanding of accessible destination experiences is needed by tourism operators" [38]. Darcy covers accessible tourism and social sustainability in other papers [39]. One article stated that "social sustainability also relates to such design perspectives required to ensure inclusion by considering underrepresented groups (e.g., accessibility for the elderly and the disabled)" [40].

Table 2. Full text hits for disab* and "social sustainability" of articles downloaded from four databases and analyzed in ATLAS.ti ${ }^{\circledR}$.

\begin{tabular}{ccc}
\hline $\begin{array}{c}\text { Article number (P and a number) } \\
\text { assigned by ATLAS.ti }\end{array}$ & Mentioning disab* & Mentioning "social sustainability" \\
\hline TOTALS: & 703 & 365 \\
P25 & 1 & 68 \\
P19 & 2 & 64 \\
P9 & 1 & 50 \\
P22 & 1 & 36 \\
P10 & 2 & 29 \\
P20 & 2 & 28 \\
P51 & 19 & 12 \\
P23 & 1 & 6 \\
P46 & 2 & 5 \\
P33 & 114 & 4 \\
P4 & 80 & 4 \\
P12 & 57 & 4 \\
P18 & 2 & 4 \\
P45 & 2 & 4 \\
P27 & 60 & 3 \\
P21 & 4 & 3 \\
P34 & 3 & 3 \\
P11 & 1 & 2 \\
P31 & 1 & bib2 \\
P7 & 200 & 1 bib \\
P5 & 40 & 1 bib \\
P29 & 11 & bib1 \\
P44 & 11 & bib1 \\
P3 & 8 & bib1 \\
\hline & & \\
\hline
\end{tabular}


Table 2. Cont.

\begin{tabular}{ccc}
\hline $\begin{array}{c}\text { Article number (P and a number) } \\
\text { assigned by ATLAS.ti }\end{array}$ & Mentioning disab" & Mentioning "social sustainability" \\
\hline P6 & 5 & bib \\
P8 & 5 & bib \\
P42 & 4 & affiliation1 \\
P50 & 4 & bib1 \\
P26 & 3 & bib1 \\
P30 & 3 & bib1 \\
P38 & 3 & bib1 \\
P28 & 2 & bib1 \\
P53 & 2 & bib1 \\
P37 & 1 & 1 \\
P49 & 1 & bib1 \\
P43 & 12 & Bib1 \\
P36 & 5 & bib1 \\
P48 & 3 & bib1 \\
P32 & 2 & bib1 \\
P4 & bib2 & bib1 \\
P2 & bib1 & bib1 \\
P24 & bib1 & bib1 \\
P35 & 1 & bib1 \\
P39 & 1 & 1 \\
P40 & bib1 & bib1 \\
\hline & & \\
\hline
\end{tabular}

Various articles were linked to design issues. Dempsey et al. highlighted that disabled people are less likely to use green spaces than non-disabled people where seating and facilities (e.g., toilets) are lacking [41]. Chan et al. in their paper Critical Factors for Improving Social Sustainability of Urban Renewal Project presented results of a questionnaire given to planners, property development managers, and local citizens in Hong Kong. Performing factor analysis they found six factors that should be incorporated for achieving social sustainability: "satisfaction of welfare requirements", "conservation of resources and the surroundings", "creation of harmonious living environment", "provisions facilitating daily life operations", "form of development" and "availability of open spaces". Under the factor of "satisfaction of welfare requirements" they listed "provisions for basic needs of disabled, elderly or children with proper access" [42]. We posit that one could have listed access for disabled people under "creation of harmonious living environment". Indeed, listing disabled people under welfare requirements could be problematic depending on how the term welfare is used. It is often used in a disempowering way highlighting a charity approach of the fortunate ones toward the unfortunate ones - the other. Hickey-Moody et al., covering the topic of design, stated that, although designers could have an impact by "promoting efficient design, ecodesign, disability-inclusive and universal design", that there is a certain resistance "because of the challenges they face in meeting the demands of consumers who are reluctant to prioritize global concerns over their individual desires" [43]. Indeed, desires of groups and individuals to keep certain privileges [18] and desires [22] makes many "global" developments problematic to achieve [44] including a global vision of social sustainability. 
Prasertsubpakij and Nitivattananon in their article Evaluating Accessibility to Bangkok Metro Systems Using Multi-Dimensional Criteria across User Groups stated that access to the metro or any rail-based transport system is still an unsolved issue in many large cities and that the Bangkok Metro system treats "women, the elderly and disabled people unfairly" [45]. They linked this unfair treatment to the focus on "promoting high usage volume for typical users" [45]. In the introduction of their article, the authors stated that accessibility "has become an increasing criticism on long-term social sustainability" [45]. On the other hand, Reeves made the point that spatial planning often forgets gender aspects but focuses more on accessibility issues [46]. According to Reeves, social sustainability is widely interpreted to mean achieving social equity and social inclusion [46]. The question is what does social equity mean and how do we achieve it? Do we start with gaining equity for the easier cases over the more difficult cases? From a design point of view disabled people pose more challenges than other social groups. Although, if something is designed from the beginning using design principles of universal design, the cost difference might not be that different in many instances, there is more than cost. Universal design requires a thorough understanding of the needs and problems of all social groups and to know about best practices. As it relates to disabled people, this requires that they are visible in all discourses. However, they are not present in many of them (e.g., [17]).

A recent online discussion highlighted many problems disabled people face related to development agendas [37]. Interestingly, Fischer et al. in their paper Quality of Life, Sustainable Civil Infrastructure, and Sustainable Development: Strategically Expanding Choice talked about the significance of Quality of Life (QOL) in infrastructure decisions making for sustainable development. They concluded "that despite its leap forward from purely objective formulations of QOL, the revealed preference paradigm is inadequate as a performance measure for sustainable development. It ignores those people who cannot make choices based on preference, for instance, due to economic disadvantage or disability, effectively ignoring any role for social equity" [47]. This suggests that QOL cannot capture various dynamics around social inequity. We posit that although QOL is used extensively related to disabled people, there are indeed various shortcomings of the instrument [48].

One paper with the title Long-Term Care: Dignity, Autonomy, Family Integrity, and Social Sustainability: The Hong Kong Experience linked social sustainability to long-term care. They found "that aging in place and family care were considered the best approaches to long term care insofar as procuring and balancing the values of dignity, autonomy, family integrity and social sustainability were concerned" [49]. However, the article does not talk further about the concept of social sustainability beyond what we quoted here. Our study found very little coverage of healthcare under social sustainability (see other areas of our article).

Sarkis et al. linked "various sustainable indicators with various reverse logistics practices to develop a profile of reverse logistics for social sustainability" [50]. The authors compiled "practical, international examples from practice and research to highlight reverse logistics for social sustainability" [50]. They mentioned a Center that is selling recyclable raw materials, claiming that this created "jobs for over 100 mentally disabled citizens who would otherwise not be in the workforce, and changing people's attitudes toward the disabled" [50]. It lists as an achievement of the Centre that it "diverts 5000 tons of monthly waste from landfills and adds to the overall quality of life. The repetitive jobs at the center train employees and the low-tech work has kept operating costs at one-tenth the amount spent for recycling in other mid-sized cities" [50]. Others suggested using 
disabled people for recycling activities (without mentioning social sustainability) [51,52]. Unfortunately, the article by Sarkis et al. does not describe in more detail the situation at the Centre such as the salaries of disabled people and it does not give evidence as to how attitudes toward "the disabled" have changed. If it is organized like sheltered workshops, there is a large body of literature that questions the practice [53-56].

To conclude the content analysis of this section, Landorf et al. stated, "[f]inally, it requires a more robust political and intellectual challenge to the prevailing theoretical constructs that currently dictate urban development policy and practice. It is here that the disability movement might be able to influence and strengthen an agenda for future action" [57]. We posit that the disability community has to find ways to influence all sustainability discourses but especially the social sustainability discourse. However, given the results, we submit that disabled people are invisible in the academic social sustainability discourse. This might not be very surprising as social sustainability has focused so far more on products and processes and less on the social (see Section 3.2. for expansion on this point); however, even if social sustainability discourses would be about social and the understanding put forward by McKenzie [4] and Vallance [3] the result might have been not much different as disabled people are invisible in many academic discourses of relevance to them that are linked to development issues [17,23,36,44,58-60]. A recent online consultation on the Post 2015 development agenda setting highlighted the invisibility as a problem for disabled people and what could and should be done to fix it [37]. In short the invisibility has to be rectified in such a way that disabled people are not only present but that they also have access to knowledge needed on a consistent level on all levels from local to global and it has to include education and capacity building components for disabled people. Given the invisibility of engagement with disabled people and their issues so far, the analysis of a given discourse through a disability studies lens gains even more importance. Given the call for papers, the following sections present an analysis of 1909 abstracts in light of the "development", "bridge" and "maintenance" aspect of social sustainability and an impact assessment through a disability studies lens on the findings. Further answered in the following sections is what challenges a disability studies lens poses for "development", "bridge" and "maintenance" aspects of social sustainability.

\subsection{Development Sustainability}

According to Vallance, Perkins, and Dixon "development sustainability" addresses basic needs, the creation of social capital, justice and so on [3]. Indicators are a set of measurement tools to assess and evaluate where one stands relative to an intended goal [61]. Indicators were mentioned $(n=343)$ in the $(n=1909)$ academic abstracts we analyzed and covered the following targets: forest industry $(n=9)$; agriculture $(n=9)$; urban infrastructure $(n=8)$; water $(n=4)$; supply chain decisions $(n=3)$; transportation $(\mathrm{n}=3)$ and fisheries $(\mathrm{n}=2)$. The following were mentioned once: detergent industry; horticultural system; biotechnology; public housing; regeneration projects; petroleum industry; biomass-to-bioproducts value chain; urban design; process industry; farming; technology assessment; social wellbeing of the urban renewal projects; bovine livestock; noise reducing devices; waste- and by-product management and energy production; energy technology; nuclear power, local energy production; renewable energy; clean development; irrigation and drainage management; river basin; rice production; food; industrial ecosystem; household services; airline; regional development; 
consumption; wildlife; rangeland health; power generation technologies; hydrogen production from solid fuels; biofuel; construction industry; reverse supply chain logistics; fair trade handicraft producers; rural economies; project baselines; natural resources; commercial property; bioethanol supply chain; pulp industry; social/community sustainability; vulnerability index; community cohesion indicator and community resilience.

The list suggests a very broad but shallow coverage of indicators needed for any given area, which we posit is a problem.

Looking at the targets of the indicators through the lens of "development sustainability" we posit that most of the indicators have little to do with the goals for "development sustainability" such as basic needs, building social capital, justice and so on. All but the following targets: social wellbeing of the urban renewal projects; housing; social/community sustainability; vulnerability index; community cohesion indicator and community resilience focus on production of a product. This, we assume, is partly due to the history of activity under social sustainability, which focused on products and processes. Our data indicates that the social sustainability academic discourse has to evolve beyond this traditional focus if one believes in the school of thought evident in the "development sustainability" concept. We posit the special issue in this present journal adds to the discussion around refocusing goals of social sustainability and as such we posit our data adds to this discussion.

From a disability studies perspective, most targets linked to the indicators are irrelevant for the goal of improving the living situation of disabled people with the caveat that if disabled people are consumers of a given products, the question of usability and affordability might arise. Given the historical focus of social sustainability as outlined in the preceding paragraph, this finding is not surprising.

However, some of the targets for indicators we found, such as: social wellbeing of the urban renewal projects; housing; social/community sustainability; vulnerability index; community cohesion indicator and community resilience are already more in sync with Vallance, Perkins, and Dixon idea of social sustainability [3] and the operationalization of indicators for these targets will directly impact disabled people and as such need direct involvement of disabled people even today. Our data suggests that disabled people are not a significant part of the academic discourses around these targets yet. Furthermore if the social sustainability focus is shifting more toward what Vallance, Perkins, and Dixon envisioned with the concept of "development sustainability" [3] and what others envision [4], more targets of indicators and indicators themselves will be developed that impact disabled people. If so, the active engagement of disabled people becomes a more pressing issue to ensure that the targets and the indicators agreed upon are of utility to disabled people. We posit that the following targets for indicators listed in [5] would be useful if they involve disabled people and generate data related to disabled people including: income, savings, education, employment, trust, connectedness, social participation, life stress, active citizenship, malnutrition, access to clean water and sanitation, access to energy, social cohesion, social acceptance and access to and accessible information. The Zero Project [8] lists various social indicators designed to complement work done by national monitoring bodies that assess the implementation of the UN Convention on the Rights of Persons with Disabilities (CRPD). We posit that these are essential social sustainability targets for disabled people to maximize the utility of social sustainability discourses and outcomes for disabled people.

Setting aside the disability studies lens, debating the scope of social sustainability through a social determinants of health (SDH) lens [7,62,63], also leads to the conclusion that the scope of social 
sustainability should change. Looking at targets for social sustainability through a SDH lens, health in general and healthcare in particular are little covered as important measures and SDH does not show up as a term in the social sustainability literature we investigated (Table 3). The Hans Böckler Foundation has initiated and funded a project to analyze the interlinkages of social sustainability with special emphasis on labor and health with economic and environmental sustainability [61]. The environment in which an individual lives is seen as having a major impact on shaping the individuals quality of life and as such their health and well-being [22,64]. This, we posit, suggests that the existing discourse of SDH $[7,62,63]$, which are indicators of health, could and should be linked to the social sustainability discourse.

Table 3. Frequency analysis of the 14 Social Determinants of Health [7] in the 1909 social sustainability abstracts.

\begin{tabular}{lc}
\hline \multicolumn{1}{c}{ Social Determinant } & Frequency \\
\hline 1. Income & 123 \\
2. Education & 206 \\
3. Unemployment \& job security & 3 \\
4. Employment (working conditions) & 61 \\
5. Childhood development & 0 \\
6. Food insecurity & 1 \\
7. Housing & 240 \\
8. Social Exclusion & 15 \\
9. Social Safety network & 0 \\
10. Health Services & 5 \\
11. Aboriginal Status & 0 \\
12. Gender & 88 \\
13. Race & 77 \\
14. Disability & 3 \\
\hline
\end{tabular}

Our results show that the abstracts of the social sustainability literature engage with some SDH such as income, housing and education but not with others such as social exclusion and health services. SDH's 1-10 could be seen as basic needs (a focus of the development sustainability concept) although not all basic needs (for example water, sanitation, energy) are covered by the SDH list; however, we posit that these are useful indicators to be added as targets for social sustainability indicators. Addressing these determinants might lessen the large gap between the quality of life of different groups of individuals [64]. Four sets of marginalized groups (Aboriginal status, disability, gender and race) are in actuality $\mathrm{SDH}$, suggesting that these groups are disadvantages simply by being themselves (interestingly disabled people are also invisible in SDH discourses [59]).

\subsection{Bridge Sustainability}

"Bridge sustainability" understands the need to connect human behavior with preserving the environment, such as development of an eco-social relationship between humans and their environment [3]. The emerging ecohealth field has as its mandate to think about interventions that improve the health and wellbeing of people, animals and ecosystems [65-67]. From a disability studies 
perspective, the problem is first that the ecohealth field perceives disabled people within a medical framework which leads to defining the problems in those terms as well as the solutions to the given problem [22]. Secondly, disabled people are fairly invisible in the eco-health discourse [22]. We posit that disabled people have something positive to contribute to the ecohealth discourse as well as to the "bridge sustainability" discourse, contributions that improve the analysis of how bridging could happen and why it is not happening. Through an ability studies lens, one can analyze how the different ability expectations intrinsic to certain schools of thought of how to deal with human-nature relationships (for example anthropocentric versus bio/ecocentric [17,22]) impact this relationship and "bridge sustainability".

\subsection{Maintenance Sustainability}

"Maintenance sustainability" refers to the preservation — or what can be sustained — of sociocultural characteristics in the face of change, and the ways in which people actively embrace or resist those changes [3]. This is an important aspect for disabled people. Linked to this understanding of maintenance is who has the power to sustain their characteristic and who does not. This is another important aspect for disabled people.

Conflicts are mentioned in numerous abstracts [68-87] ranging from "whether the discourse of corporate social responsibility will improve understanding among stakeholders and lead to mutually acceptable resolutions to conflict" [68] to "educational simulation tool for negotiating sustainable natural resource management strategies among stakeholders with conflicting interests" [69]. We submit that many possible conflicts are not mentioned in the documents. In particular, no engagement has happened yet to look into the ability expectation conflicts between the able-bodied and disabled people within the social sustainability discourse or for that matter into ability expectation differences between differently able-bodied groups. Indeed, the question is: which ability expectations can be sustained and which ability expectations are up for negotiation? Can we sustain the ability expectation of competitiveness or the ability expectation of consumption; are they on the negotiation table? Who has to change one's ability expectations? Here we posit it seems that it is expected that the vulnerable have to change more. Resilience is often used within sustainability discourses [88,89] and community resilience was one of the indicators covered in our abstracts. However who has to become resilient related to what? Resilience discourses often promote certain abilities one has to accept and has to adapt to; advancing the narrative of certain ability expectations which may be detrimental to disabled people [90]. We submit the social sustainability discourse, and in the end all sustainable development discourses, would benefit from generating ability conflict maps and based on such maps would benefit from trying to develop ability conflict resolution mechanisms (making this argument for the education for sustainable development discourse see [17]). These mechanisms very likely would be different than the ones in existence, such as the ones based on differential access to natural resources [91].

\section{Conclusions and Further Research}

We present in this paper evidence of the invisibility of disabled people and their views in the academic social sustainability literature. Within much of the literature, there is the overarching theme that social sustainability indicators are lacking and we as researchers need to find ways to quantify 
already existing qualitative indicators [61]. If we look at the coverage of disabled people through the lens of indicators for social sustainability put forward by McKenzie [4], none but equity to access to some key services (transport, recreation) were addressed. We posit that we have to add indicators to the social sustainability discourse that reflect the lived experience of disabled people such as described in [8]). We, as well as others [11,37], posit that we need to monitor and implement existing indicators in such a way that they generate useful data related to disabled people.

Vallance, Perkins and Dixon, indicate that there are conflicts between the different SD pillars (environmental, economic and social) and between the three prongs they generated, encompassing "development", "bridge" and "maintenance" sustainability [3]. Adding disabled people adds a new source of conflict into the mix; however we submit that disabled people also contribute an analytical lens (ability expectation and ableism) that we posit is useful to further the discourse around the different SD pillars and their relation with each other, and enrich the model put forward by Vallance et al. Looking at it from an ability expectation and ableism lens allows one to pinpoint problems that lead to ability expectation based conflicts and finding solutions to decrease ability expectation conflicts [17]. Indeed, we posit that there is a need to generate ability expectation conflict maps and ability expectations conflict resolution mechanisms for all SD discourses individually (first suggested for education for sustainable development in [17]) and for maps and resolutions dealing with ability conflicts between SD discourses.

\section{Acknowledgments}

This work was in part supported by a Bachelor of Health Sciences Undergraduate Research fellowship (University of Calgary) for TR. We also want to thank the University of Calgary for paying the open access fees for this article.

\section{Conflicts of Interest}

The authors declare no conflict of interest.

\section{References and Notes}

1. World Commission on Environment and Development (WCED). Report of the World Commission on Environment and Development: Our Common Future. Availabe online: http://www.un-documents.net/our-common-future.pdf (accessed on 1 November 2013).

2. United Nations Sustainable Development Knowledge Platform Home Page. Available online: http://sustainabledevelopment.un.org/resources.html (accessed on 1 November 2013).

3. Vallance, S.; Perkins, H.C.; Dixon, J.E. What is social sustainability? A clarification of concepts. Geoforum 2011, 42, 342-348.

4. McKenzie, S. Social Sustainability: Towards Some Definitions; University of South Australia: Adelaide, Australia, 2004.

5. Dreyer, M.; Mays, C.; Sellke, P.; Renn, O.; Kuhn, R.; Schröter, R.; Hausschild, M.; Dreyer, L.; Wangel, A.; Antunes, P. Literature Review on Social Indicators and Integrated Model of Indicator 
Selection. Availabe online: http://www.prosuite.org/c/document_library/get_file?uuid=d1b91384d89b-4988-8f87-5806020b8874\&groupId=12772 (accessed on 1 November 2013).

6. Benoît, C.; Vickery-Niederman, G. Social Sustainability Assessment Literature Review. Availabe online: http://www.sustainabilityconsortium.org/wp-content/themes/sustainability/assets/pdf/ whitepapers/Social_Sustainability_Assessment.pdf (accessed on 1 November 2013).

7. The Commission on Social Determinants of Health Knowledge Networks. Improving Equity in Health by Addressing Social Determinants. Available online: whqlibdoc.who.int/publications/ 2011/9789241503037_eng.pdf (accessed on 19 September 2013).

8. Zero Project. Social Indicators. Available online: http://www.zeroproject.org/indicators/ (accessed on 19 September 2013).

9. United Nations Enable. Convention on the Rights of Persons with Disabilities. Available online: http://www.un.org/disabilities/default.asp?navid=14\&pid=150 (accessed on 19 September 2013).

10. United Nation Enable. The Millennium Development Goals (MDGs) and Disability. Available online: http://www.un.org/disabilities/default.asp?id=1470\#about (accessed on 19 September 2013).

11. United Nation Secretary General. Keeping the promise: Realizing the Millennium Development Goals for persons with disabilities towards 2015 and beyond. Available online: http://www.un.org/disabilities/documents/gadocs/a_65_173.doc (accessed on 19 September 2013).

12. High-Level Panel of Eminent Persons on the Post-2015 Development Agenda. A new global partnership: Eradicate poverty and transform economics through sustainable development. Available online: http://www.un.org/sg/management/pdf/HLP_P2015_Report.pdf (accessed on 19 September 2013).

13. Wolbring, G. Eco-ableism. Anthropology News, 14 September 2012.

14. Wolbring, G. Expanding ableism: Taking down the ghettoization of impact of disability studies scholars. Societies 2012, 2, 75-83.

15. Society for Disability Studies. Mision and History. Available online: http://www.disstudies.org/ about/mission-and-history (accessed on 19 September 2013).

16. Wolbring, G. Why NBIC? Why human performance enhancement? Innov. Eur. J. Soc. Sci. Res. 2008, 21, 25-40.

17. Wolbring, G.; Burke, B. Reflecting on education for sustainable development through two lenses: Ability studies and disability studies. Sustainability 2013, 5, 2327-2342.

18. Wolbring, G. Ability privilege: A lens to analyse social justice issues of humans, animals and nature: A needed addition to privilege studies. J. Crit. Anim. Stud. 2013, in press.

19. Wolbring, G.; Leopatra, V.; Noga, J. The sentiment of waste and the measure of footprints evaluated through an ableism lens. Eubios J. Asian Int. Bioethic. 2012, 22, 117-123.

20. Wolbring, G. Ableism and energy security and insecurity. Stud. Ethics, Law, Technol. 2011, doi:10.2202/1941-6008.1113.

21. Noga, J.; Wolbring, G. An analysis of the united nations conference on sustainable development (Rio+20) discourse using an ability expectation lens. Sustainability 2013, 5, 3615-3639.

22. Wolbring, G. Ecohealth through an Ability Studies and Disability Studies Lens (in print). In Ecological Health: Society, Ecology and Health; Gislason, M.K., Ed.; Emerald: London, UK, 2013; Volume 15, pp. 91-107. 
23. Wolbring, G. Water discourse, ableismc and disabled people: What makes one part of a discourse? Eubios J. Asian Int. Bioethic. 2011, 21, 203-207.

24. Yergens, D.R.J.; Doig, C.J. KSv2: Application for Enhancing Scoping and Systematic Reviews. In Proceedings of American Medical Informatics Association (AMIA) 2012 Annual Symposium, Chicago, IL, USA, 3-7 November 2012; AMIA: Bethesda, MD, USA, 2012.

25. Koenig, T. Routinizing Frame Analysis through the Use of CAQDAS. Available online: http://www.restore.ac.uk/lboro/research/methods/routinizing_frame_analysis_RC33.pdf (accessed on 1 November 2013).

26. MacMillan, K. More than just coding? Evaluating CAQDAS in a discourse analysis of news texts. Forum Qual. Soc. Res. 2005, 6, Article 25.

27. Harrison, J. Abandoned bodies and spaces of sacrifice: Pesticide drift activism and the contestation of neoliberal environmental politics in California. Geoforum 2008, 39, 1197-1214.

28. Stamford, L.; Azapagic, A. Sustainability indicators for the assessment of nuclear power. Energy 2011, 36, 6037-6057.

29. Shreck, A.; Getz, C.; Feenstra, G. Social sustainability, farm labor, and organic agriculture: Findings from an exploratory analysis. Agric. Hum. Value 2006, 23, 439-449.

30. Dowler, E.; Kneafsey, M.; Cox, R.; Holloway, L. 'Doing food differently': Reconnecting biological and social relationships through care for food. Soc. Rev. 2009, 57, 200-221.

31. Prudham, S. Tall among the trees: Organizing against globalist forestry in rural British Columbia. J. Rural Stud. 2008, 24, 182-196.

32. Trani, J.F.; Bakhshi, P.; Noor, A.A.; Mashkoor, A. Lack of a will or of a way\&quest; Taking a capability approach for analysing disability policy shortcomings and ensuring programme impact in Afghanistan. Eur. J. Dev. Res. 2009, 21, 297-319.

33. Ahlberg, M.; Turja, L.; Robinson, J. Educational research and development to promote sustainable development in the city of helsinki: Helping the accessible helsinki programme 2001-2011 to achieve its goals. Int. J. Env. Sustain. Dev. 2003, 2, 197-209.

34. Darcy, S. Inherent complexity: Disability, accessible tourism and accommodation information preferences. Tourism Manag. 2010, 31, 816-826.

35. El-Geneidy, A.; Cerdá, A.; Fischler, R.; Luka, N.; de Transport, A.M.; El-Geneidy, A.M. Evaluating the impacts of transportation plans using accessibility measures. Can. J. Urban Res. 2011, 20, 81-104.

36. Noga, J.; Wolbring, G. The economic and social benefits and the barriers of providing people with disabilities accessible clean water and sanitation. Sustainability 2012, 4, 3023-3041.

37. Disability inclusive development agenda towards 2015 \& beyond. Available online: http://www.worldwewant2015.org/node/314874 (accessed on 19 September 2013).

38. Darcy, S.; Cameron, B.; Pegg, S. Accessible tourism and sustainability: A discussion and case study. J. Sustain. Tourism 2010, 18, 515-537.

39. Wearing, S.; Darcy, S. Inclusion of the "Othered" in tourism. Cosmop. Civil Soc.: Interdiscip. J. 2011, 3, 18-34.

40. Valdes-Vasquez, R.; Klotz, L.E. Social sustainability considerations during planning and design: Framework of processes for construction projects. J. Construc. Eng. Manag. 2012, 139, 80-89. 
41. Dempsey, N. Quality of the built environment in urban neighbourhoods. Plann. Prac. Res. 2008, 23, 249-264.

42. Chan, E.; Lee, G.K.L. Critical factors for improving social sustainability of urban renewal projects. Soc. Indic. Res. 2008, 85, 243-256.

43. Hickey-Moody, A.; Wood, D. Virtually sustainable: Deleuze and desiring differenciation in Second Life. Continuum: J. Media Cult. Stud. 2008, 22, 805-816.

44. Wolbring, G. Citizenship education through an ability expectation and "Ableism" lens: The challenge of science and technology and disabled people. Educ. Sci. 2012, 2, 150-164.

45. Prasertsubpakij, D.; Nitivattananon, V. Evaluating accessibility to Bangkok metro systems using multi-dimensional criteria across user groups. IATSS Res. 2012, 36, 56-65.

46. Reeves, D. Mainstreaming gender equality: An examination of the gender sensitivity of strategic planning in Great Britain. Town Plann. Rev. 2002, 73, 197-214.

47. Fischer, J.M.; Amekudzi, A. Quality of life, sustainable civil infrastructure, and sustainable development: Strategically expanding choice. J. Urban Plann. Dev. 2011, 137, 39-48.

48. Wolbring, G. The Triangle of Enhancement Medicine, Disabled People, and the Concept of Health: A New Challenge for HTA, Health Research, and Health Policy. Available online: http://www.ihe.ca/documents/HTA-FR23.pdf (accessed on 1 November 2013).

49. Chan, H.M.; Pang, S. Long-term care: Dignity, autonomy, family integrity, and social sustainability: The Hong Kong experience. J. Med. Philos. 2007, 32, 401-424.

50. Sarkis, J.; Helms, M.M.; Hervani, A.A. Reverse logistics and social sustainability. Corp. Soc. Responsib. Environ. Manag. 2010, 17, 337-354.

51. Stone, C. Environmental consequences of heavy-industry restructuring and economic regeneration through industrial ecology. Min. Tech. 2002, 111, 187-191.

52. Iskandar, L. Adult Learning and Poverty Alleviation in Egypt. Available online: http://www.unesco.org/education/uie/pdf/adedandpovertyreduction.pdf\#page=22 (accessed on 1 November 2013).

53. Eicker, A.; Schneider, S. Production-orientated education and training of the mentally disabled in sheltered employment (PIONIER). Disabil. Rehabil. 2000, 22, 206-210.

54. Gill, M. The myth of transition: contractualizing disability in the sheltered workshop. Disabil. Soc. 2005, 20, 613-623.

55. Butcher, S.; Wilton, R. Stuck in transition? Exploring the spaces of employment training for youth with intellectual disability. Geoforum 2008, 39, 1079-1092.

56. Wendt, S. Reform steps toward networking sheltered workshops and the general labour market. Rehabilitation 2010, 49, 38-47.

57. Landorf, C.; Brewer, G.; Sheppard, L.A. The urban environment and sustainable ageing: Critical issues and assessment indicators. Local Environ. 2008, 13, 497-514.

58. Wolbring, G.; Leopatra, V.; Yumakulov, S. Climate change, water, sanitation and energy insecurity: Invisibility of people with disabilities. Can. J. Disabil. Stud. 2012, 1, 66-90.

59. Wolbring, G. People with disabilities and social determinants of health discourses. Can. J. Public. Health. 2011, 102, 317-319. 
60. Wolbring, G. A culture of neglect: Climate discourse and disabled people. Available online: http://dspace.ucalgary.ca/bitstream/1880/47465/1/wolbringclimate.pdf (accessed on 19 September 2013).

61. Omann, I.; Spangenberg, J.H. Assessing Social Sustainability The Social Dimension of Sustainability in a Socio-Economic Scenario. In Assessing Social Sustainability, Proceedings of the 7th Biennial Conference of the International Society for Ecological Economics, Sousse, Tunisia, 6-9 March 2012. Available online: http://seri.at/wp-content/uploads/2010/05/Assessing social_sustainability.pdf (accessed on 19 September 2013).

62. Mikkonen, J.; Raphael, D. Social Determinants of Health The Canadian Facts. Available online: http://www.thecanadianfacts.org/The_Canadian_Facts.pdf (accessed on 19 September 2013).

63. Centers for Disease Control and Prevention (USA). Social Determinants of Health Centers for Disease Control and Prevention. Available online: http://198.246.98.21/DHDSP/library/ maps/social_determinants.htm (accessed on 19 September 2013).

64. Raphael, D. Social determinants of health: Present status, unanswered questions, and future directions. Int. J. Health Serv. 2006, 36, 651-677.

65. Wilcox, B.A.; Aguirre, A.A.; Daszak, P.; Horwitz, P.; Martens, P.; Parkes, M.; Patz, J.A.; Waltner-Toews, D. EcoHealth: A transdisciplinary imperative for a sustainable future. Ecohealth 2004, 1, 3-5.

66. Butler, C.D.; Weinstein, P. Global ecology, global health, ecohealth. Ecohealth 2011, 8, 253-254.

67. Charron, D.F. Ecosystem approaches to health for a global sustainability agenda. Ecohealth 2012, 9, 1-11.

68. Hutchins, M.J.; Sutherland, J.W. An exploration of measures of social sustainability and their application to supply chain decisions. J. Cleaner Prod. 2008, 16, 1688-1698.

69. García-Barrios, L.E.; Speelman, E.N.; Pimm, M.S. An educational simulation tool for negotiating sustainable natural resource management strategies among stakeholders with conflicting interests. Ecol. Model. 2008, 210, 115-126.

70. Mestrum, F. Poverty Reduction and Sustainable Development. In The World Summit on Sustainable Development; Springer: New York, NY, USA, 2005; pp. 35-55.

71. Lee, Y.; Kim, K.; Lee, S. Study on building plan for enhancing the social health of public apartments. Build. Environ. 2010, 45, 1551-1564.

72. Herzig, C.; Godemann, J. Internet-supported sustainability reporting: Developments in Germany. Manage. Res. Rev. 2010, 33, 1064-1082.

73. Silva, E. The politics of sustainable development: native forest policy in Chile, Venezuela, Costa Rica and Mexico. J. Latin. Am. Stud. 1997, 457-493.

74. Hahn, T.; Figge, F.; Pinkse, J.; Preuss, L. Trade-offs in corporate sustainability: You can't have your cake and eat it. Bus. Strat. Environ. 2010, 19, 217-229.

75. Zeppel, H. Managing cultural values in sustainable tourism: Conflicts in protected areas. Tourism Hospit. Res. 2010, 10, 93-115.

76. Wade-Benzoni, K.A. A golden rule over time: Reciprocity in intergenerational allocation decisions. Acad. Manag. J. 2002, 45, 1011-1028.

77. Lund, V.; Röcklinsberg, H. Outlining a conception of animal welfare for organic farming systems. J. Agr. Environ. Ethics 2001, 14, 391-424. 
78. Landorf, C. Evaluating social sustainability in historic urban environments. Int. J. Herit. Stud. 2011, 17, 463-477.

79. Korthals, M. Ethical rooms for maneuver and their prospects vis-à-vis the current ethical food policies in Europe. J. Agr. Environ. Ethics 2008, 21, 249-273.

80. Michalski, W.; Miller, R.; Stevens, B. Towards the creative society: 21 st century social dynamics. Foresight 2000, 2, 85-94.

81. Smith, A. The Third Sector, regeneration and sustainable communities: "Rolling" with the New Labour agenda. Int. J. Sociol. Soc. Pol. 2010, 30, 48-65.

82. Lockie, S. Capturing the sustainability agenda: Organic foods and media discourses on food scares, environment, genetic engineering, and health. Agr. Hum. Val. 2006, 23, 313-323.

83. Hansmann, R.; Mieg, H.A.; Frischknecht, P. Principal sustainability components: Empirical analysis of synergies between the three pillars of sustainability. Int. J. Sustain. Dev. World Ecol. 2012, 19, 451-459.

84. Fuchs, C.; Bichler, R.M.; Raffl, C. Cyberethics and co-operation in the information society. Sci. Eng. Ethics 2009, 15, 447-466.

85. Ridley, A. The role of farming systems group approaches in achieving sustainability in Australian agriculture. Anim. Produc. Sci. 2005, 45, 603-615.

86. Reis, A.C.; Higham, J.E.S. Recreation conflict and sport hunting: Moving beyond goal Interference towards social sustainability. J. Sport Tourism 2009, 14, 83-107.

87. Wissenburg, M. Global and ecological justice: prioritising conflicting demands. Environ. Val. 2006, 425-439.

88. Brasche, I. Cultural resilience and social wellbeing: A case for research on Groote Eylandt. Aust. Aborig. Stud. 2008, 26, 93-98.

89. Beckman, M. Converging and conflicting interests in adaptation to environmental change in central Vietnam. Clim. Dev. 2011, 3, 32-41.

90. Hutcheon, E.; Wolbring, G. Deconstructing the resilience concept using an ableism lens: Implications for people with diverse abilities. Dilemata 2013, 5, 235-252.

91. Humphreys, M. Natural resources, conflict, and conflict resolution uncovering the mechanisms. J. Conflict Resolut. 2005, 49, 508-537.

(C) 2013 by the authors; licensee MDPI, Basel, Switzerland. This article is an open access article distributed under the terms and conditions of the Creative Commons Attribution license (http://creativecommons.org/licenses/by/3.0/). 